Title page

(i) Short informative title: Environmental warming responses of Brachyscome daisy species

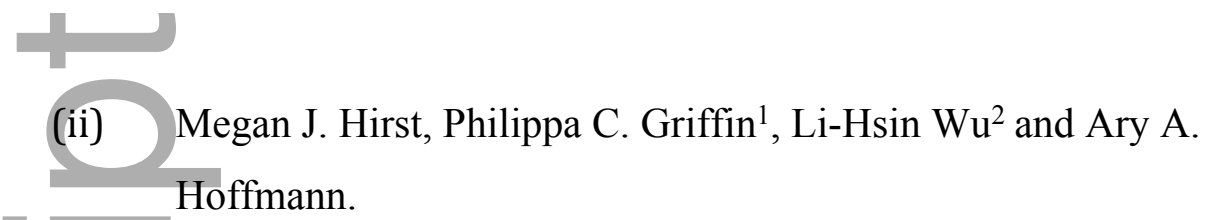

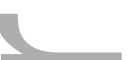

(iii) 1. Bio21 Institute, School of Biosciences, The University of

Melbourne, Parkville, 3010, Victoria, Australia

2. The Royal Botanic Gardens Victoria-Cranbourne, Cnr Ballarto Road and Botanic Drive, Cranbourne, 3977, Victoria, Australia.

(iv) Megan J. Hirst (MJH)

1. Royal Botanic Gardens Victoria, Private Bag 2000, Birdwood Ave, Melbourne 3000.

2. Megan.Hirst@rbg.vic.gov.au

3. +61488330578

(v) Acknowledgements:

2 (This

This research was funded through an Australian Postgraduate Award and a Holsworth Wildlife Research Endowment (MJH). We thank Rodger Elliot, the Garden Ambassadors, and the Growing Friends of the Cranbourne Botanic Gardens for their ongoing support and enthusiasm for the Royal Botanic Gardens Cranbourne (RBGC)

\footnotetext{
${ }^{1}$ Philippa C. Griffin. Current affiliation: Department of Agriculture and Water Resources, GPO Box 858, Canberra City ACT 2601, Australia

${ }^{2}$ Li-Hsin Wu. Current affiliation: Department of Plant Medicine, National Pintung University of Science and Technology, Pintung 91201, Taiwan.
}

This is the author manuscript accepted for publication and has undergone full peer review but has not been through the copyediting, typesetting, pagination and proofreading process, which may lead to differences between this version and the Version of Record. Please cite this article as doi: 10.1111/AEC.12885

This article is protected by copyright. All rights reserved 
outdoor research garden. We thank our colleagues of the Royal Botanic Gardens Victoria and the Hoffmann Lab (Bio 21), and members of the Australian Seedbank Partnership. We thank Michael Nash and Warren Worboys for their assistance in setting up the RBGC

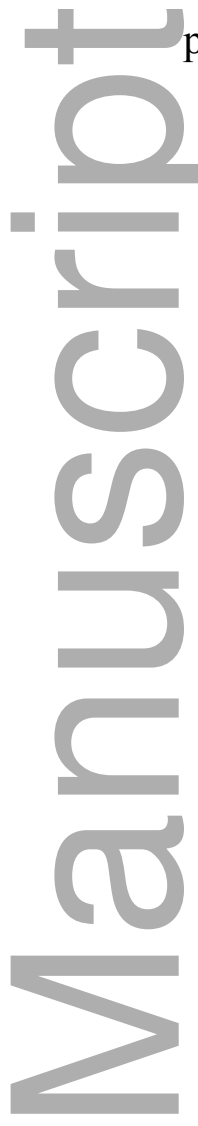
plots, and to Bronwyn Swartz for site maintenance.

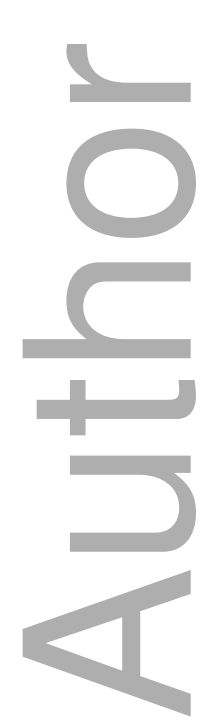


MS. MEGAN JANE HIRST (Orcid ID : 0000-0003-3822-8724)

PROF. ARY HOFFMANN (Orcid ID : 0000-0001-9497-7645)

4

5

Article type : Research Article

7

8

Megan J. Hirst ${ }^{1,2, *}$, Philippa C. Griffin ${ }^{1}$, Li-Hsin Wu ${ }^{1}$ and Ary A. Hoffmann ${ }^{1}$

12

\section{Testing the environmental warming responses of Brachyscome daisy species using a common garden approach}

${ }^{1}$ Bio21 Institute, School of Biosciences, the University of Melbourne, Parkville, 3010, Victoria, Australia.

${ }^{2}$ The Royal Botanic Gardens of Victoria, Melbourne, 3141, Victoria, Australia.

* Corresponding author. Email: Megan.Hirst@rbg.vic.gov.au

\section{Abstract.}

As temperatures increase in a warming world, there will be different responses among related plant species, with some species able to increase growth rate under warmer conditions and others less likely. Here we identify survival and growth parameters in a group of 19 related Australian daisies from the genera Brachyscome and Pembertonia when exposed to higher soil temperature, focusing particularly on species from the alpine environment. 
We used a common garden approach to measure growth and survival under warming. We tested for the effects of evolutionary history by investigating phylogeny and testing for a phylogenetic signal, and for the effects of ecological history by considering climatic variables associated with species distributions in their native range.

Evolutionary history did not have a detectable effect on warming responses. While there was a moderate signal for plant growth in the absence of warming, there was no signal for growth changes in response to warming, despite variability among species to warming that ranged from positive to negative growth responses. There was no strong effect of climate context, as species that showed a positive response to warming did not necessarily originate from hotter environments. In fact, several species from hot environments grew relatively poorly when exposed to higher soil temperature. However, species endemic to alpine areas were less likely to benefit from warming than widespread species. We found a strong phylogenetic signal for climate history, in that closely related species tend to occur in areas with similar annual variability in precipitation.

Species differences in response to soil warming were variable and difficult to link to climate conditions except for the poor response of alpine endemics. There was no significant association between survival and warming responses of species. However, as some species showed weak growth responses, this may reduce their fitness into the future.

Key words: Brachyscome, climate change, common garden, environmental variables, growth and warming responses.
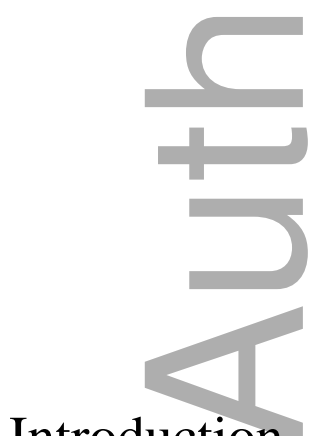

\section{Introduction}

In Australia, there are documented ecological changes in response to global warming at the species and ecosystem level that include changes in phenology, effects on species health and 
abundance, and disease incidence (Hughes et al., 2017, Pollock 2017, Hoffmann et al., 2019). For plant populations, high temperature extremes can be stressful by causing direct damage (Bita and Gerats, 2013), while increases in average temperature can influence flowering time, flowering duration and growth (Hatfield and Prueger, 2015), which can indirectly affect plant health by causing a temporal mismatch with herbivores and pollinators (Cornelissen, 2011, Forrest, 2015).

These effects in turn can alter competitive interactions among species and system processes (Pearson et al., 2013). Warmer temperatures are also expected to increase the rate of decomposition in soils, decrease soil moisture and cause nitrogen release which in turn may further alter plant growth (Shaver et al., 2000). An initial step in evaluating the response of plants under warming is to consider their response to key environmental variables including soil temperature and precipitation (Rustad et al., 2001, Cowles et al., 2018). Interactions between these variables are not expected to change equally (IPCC 2013) so experimental manipulations such as open top chambers (OTC) (Cowles et al., 2018), infrared heating (IR) (Kimball et al., 2017, Moni et al., 2019), and common garden experiments (Manzanedo et al., 2018) can be useful tools to better understand and predict responses.

The ability of a species to grow faster under warmer conditions may depend on a variety of attributes, which in turn can be shaped by evolution (Pärtel et al., 2007), the nature of the environment from which the species originates (Tilman et al., 1996) and the interaction between them (Becklin et al., 2016). Closely-related species with a shared evolutionary history may be more likely to respond in a similar manner to climate change (Willis et al., 2008) due to a shared history of selection pressures or genetic constraints. Species that occupy larger geographic areas may respond in a more positive way to warming than restricted species that occupy narrow habitats, particularly if the former have higher levels of plasticity (Gratani, 2014). On the other hand, specialist species may have attributes favored under warm conditions depending on their origin (like high drought tolerance in specialist species from arid environments) (Chesson et al., 2004).

In an attempt to separate the effects of evolutionary history from the environment where plants originate, we focus on responses to warming using the iconic Australian daisy genus Brachyscome as a study group. This group includes species used in ornamental horticulture as 
well as threatened species (Hirst, 2012) and can be found in approximately 75 per cent of regions in the Interim Biogeographic Regionalisation for Australia (IBRA), a classification system that identifies geographically distinct Australian bioregions based on climate, geology, landform, vegetation and species. Across the group there is variation in niche breadth and range size (Fig. S1) with many regionally endemic species, including species only found in alpine zones. Some species require critical attention; for example, there are currently five Brachyscome species on the Flora and Fauna Guarantee Act 1988 Threatened List (2018) in contrast to other widespread Brachyscome species that occur in many habitats over large geographic areas.

Here we explore species responses within Brachyscome as a case study and focusing particularly on species from an alpine environment versus widespread species. The following questions were considered:

1. Do Brachyscome species differ in their response to soil warming? How do warming responses in the alpine endemics compare with others in the group?

2. Is there a phylogenetic signal for warm temperature responses in Brachyscome, such that related species show similar warming responses? And further, do climatic variables associated with geographic distribution show a phylogenetic signal?

3. What are the best climatic variables associated with warming responses in Brachyscome? Do species that show a positive response naturally occupy a hotter environment or a more variable environment, or is a warming response related to the geographic area and particularly the alpine area?

4. Is the above ground warming response associated with a different bioclimatic variable than the below ground response? For example, is the root growth response to warming predicted by a separate set of variables from that determining shoot growth?

\section{Methods}

Study species

The Brachyscome study group consisted of 19 species of perennial daisies (see Table 1) selected across taxonomic groups (Short 2014). Eighteen of these are members of Brachyscome. The nineteenth, Pembertonia latisquamea (F. Muell.) P. S. Short, was originally placed within Brachyscome (as Brachyscome latisquamea). It was moved to the new monotypic genus 
Pembertonia due to its woody shrub-like form and the long oblong appendages on the style of the disc florets (Short, 2004). For clarity in this paper, we refer to the 19 study species collectively as belonging to Brachyscome, unless Pembertonia is specified.

In this study, we use the term "generalist" to indicate a species occupying a broad geographic range, which implies a species may have a greater potential to tolerate extreme abiotic conditions. The term "specialist" is used to indicate species restricted to very few habitat types (for example an alpine endemic), which usually implies a smaller range size, and may indicate a lower potential to tolerate extreme abiotic conditions than a "generalist species". We classified each of the 19 species as either a generalist $(\mathrm{G})$ or specialist $(\mathrm{S})$ based on occurrence data (see supplemental material) and how many distinct Australian bioregions were occupied. A species occupying $>6$ IBRA bioregions was considered a generalist, and a species occupying $\leq 4$ IBRA bioregions was considered a specialist. Of the 19 species, eleven were classified as generalist and eight were classified as specialist species (Table 1). Twelve species occurred in an alpine environment (Table 1), of which seven also occurred in other regions, and were therefore not endemic to an alpine environment. Only five species were considered "alpine endemics" and classified as specialist species, as were the rare species Brachyscome obovata (confined to wet, peaty ground and Sphagnum bogs), B. salkiniae (found in forest and woodlands on sandy or loamy soil and also associated with river flats) and Pembertonia latisquamea (endemic to Western Australia and found growing in coastal calcareous sand, and to a lesser extent on red brown sand further inland). Brachyscome multifida, a generalist, is widely used as a commercial bedding plant (Table 1). Cultivars of B. multifida can be found growing in landscaped areas within the grounds of Royal Botanic Gardens Cranbourne where the common garden experiment took place. As B. multifida cultivars are marketed for their robust and minimal maintenance habit (Salkin et al., 1995), we were interested in how wild-collected seed of this species would perform given no prior breeding had taken place. We hypothesized wild collected seed of B. multifida would show a positive response to warming and thus support the reasoning behind its strong horticultural merit as an ornamental plant.

Occurrence data

Species distribution records were downloaded from the Australian Virtual Herbarium (https://avh.chah.org.au/) in conjunction with the Atlas of Living Australia 
(http://spatial.ala.org.au/) and screened for duplicates, and incorrect records (e.g. coordinates located in the ocean) were removed. Records that contained a full scientific name and GPS coordinates were retained. In the case of Brachyscome spathulata, all herbarium records of the Tasmanian B. spathulata var. glabra were included given B. spathulata var. glabra is now recognised as Brachyscome spathulata. As Brachyscome paludicola, B. foliosa, and B. barkerae are relatively new specific epithets (see Short 2014), checks were also performed on their previous taxonomic names (B. basaltica var. gracilis, B. sp. 3 and B. sp. 1 respectively) and records were combined where appropriate. All species distribution data was compared with Short (2014) for validation (see Fig. S1).

Common garden warming experiment

To measure the growth potential of the 19 study species under increased soil temperature in a garden setting, we established a common garden experiment involving garden beds within raised outdoor planter boxes at the Royal Botanic Gardens Cranbourne (RBGC). RBGC is located 45 $\mathrm{km}$ southeast of the Melbourne city centre $\left(38.13^{\circ} \mathrm{S}, 145.26^{\circ} \mathrm{E}\right.$ and $85 \mathrm{~m}$ above sea level).

Seeds were collected from the wild (see Table S1 for accession details). Three to five seeds from each collection were sown under nursery conditions into Jiffy $30 \mathrm{~mm}$ pellet packs (Jiffy Products International BV The Netherlands). The accessions for species with more than one collection were mixed, as the focus in this study is on species differences rather than on population variation. Germination and early cotyledon growth occurred over a six-week period and seedlings were thinned to allow only one seedling per plug. A weak solution of seaweed-based plant fertilizer was applied to the seedlings two weeks' post-germination. At the four-leaf stage or when seedlings were approximately $4 \mathrm{~cm}$ in height, seedlings were placed outdoors for a further 14 days to harden. A total of 3,345 seedlings were planted in autumn 2013 in raised, open-air planter boxes. Each of the nine planter boxes was split, with one section subject to ambient temperatures (no warming) and the other section warmed by heating cables mounted on wire mesh positioned $150 \mathrm{~mm}$ beneath the soil surface. This setup maintains a soil temperature $4^{\circ} \mathrm{C}$ above the ambient soil temperature. We controlled the heat source through a 240 -volt plugin digital indicating controller (Shinko Technos, Osaka, Japan) and monitored the soil temperature with in-ground temperature sensors using a single wireless data logger (Watermark, Riverside, California). In each of the 18 blocks ( 2 blocks per planter box), 186 seedlings were 
planted, with species randomised within each block. The total number of each species within each planter box varied due to seed availability at the beginning of the experiment (Table S2). The lowest number of individuals was 16 for Pembertonia latisquamea. The average number of individuals per species was 176. This meant that between 2 to 38 individual plants per species per treatment (warming/no warming) were tested in any given plot. The s oil in the planter boxes was a mix of one-part brown coal, one-part double-composted mulch, and eight parts sand (as in Hirst et al., 2016). The drip irrigation in the planter boxes was set to release $0.185 \mathrm{~L}$ of water per second for three minutes. After the first watering, a ten-minute waiting period ensured absorption of the water into the soil, after which time another three-minute water delivery occurred. Initially, the water cycle occurred once a day in the afternoon. As the project progressed, and seasonal rain increased, it was found through soil moisture measurements using a Theta ML2 hand held probe that the natural rainfall adequately soaked the planter boxes and the irrigation regime was not required. Perimeter fencing was constructed around the site of the planter boxes, to prevent herbivores entering from the adjoining nature reserve.

We measured plant survival directly after transplantation in autumn 2013 as well as in the following spring, summer, early autumn and late autumn 2014. We undertook the following measurements (using digital calipers) in spring 2013 and autumn 2014 (excluding plant height at the transplant phase): plant height, plant width, and longest leaf length. We also recorded mortality. After the common garden experiment finished in late autumn 2014 (after 14 months), all surviving individuals were harvested, soil was removed, and the primary root length recorded (using a 30-cm metal ruler attached to a measuring board).

\section{Statistical analysis}

\section{Survival}

To determine if there were species differences over the course of the soil warming experiment in survival, we treated survival as a dichotomous variable measured at each census point. In comparing plant survival at one census point, we excluded plants that had died at the previous census point. We then ran a logistic generalised linear model for each census point. Plot (planter box) was included as a random variable in these analyses, while warming and species were included as factors. These analyses were run using IBM SPSS Statistics (version 24). 


\section{Warming response}

We $\log _{10}$-transformed the raw data for plant height, plant width, longest leaf length and root length for all surviving plants to ensure normality by Shapiro-Wilks tests. Due to processing damage, the roots of $\mathrm{B}$. tesquorum were excluded from the root length response. We computed the mean for each growth trait (height, width, and leaf length) of the study species under control ( $\mathrm{A}=$ no warming $)$ or warming $(\mathrm{B}=$ warming $)$ conditions at two census points (spring and autumn), and calculated the warming response in spring and autumn as $\mathrm{A}-\mathrm{B}$. Based on these values, we visualized the study species as showing negative, neutral or positive warming responses for each trait (Fig. $1 \mathrm{~A}-\mathrm{D})$.

General linear models (GLMs) run in IBM SPSS Statistics (version 24) were used to compare species for their above and below ground growth response to warming (as measured by plant width, height, leaf length and root length). To test whether the alpine endemics showed a different response to warming from the other species, and to test whether generalists showed a different response from specialists, we included alpine endemic vs. others, or generalist vs. specialist as a categorical variable in the model, with species as a nested factor within these groups. Warming was also included as a factor in these analyses along with plot. We were particularly interested in interactions between warming and species or generalist/specialist groups as such interactions would enable predicting different growth responses for different groups under warming conditions. Because multiple traits were scored, we focus on effects that remain significant after Bonferroni correction (Sokal and Rohlf, 2012). Effect sizes were summarized as percent change relative to unheated controls and the difference between means divided by the average standard deviation of the groups being compared.

\section{Correlations and environmental associations}

To test whether particular environmental variables could be related to traits and warming responses, we used the cleaned presence-only occurrence data for each of the 19 study species and downloaded the 19 bioclimatic (BIO) variables (https://www.climond.org/BioclimRegistry.aspx) associated with each distribution point from the Atlas of Living Australia (http://spatial.ala.org.au/). We then ran an Environmental Niche Factor Analysis (ENFA), with a suitable background layer based on the Köppen Climate Classification System using the adehabitat $\mathrm{R}$ package (Calenge, 2006). We randomly selected 10,000 
background points within this area and compared the 19 bioclimatic variables between the background points and the known distribution points of the 19 species. By comparing the distribution of the ecogeographical variables between the presence data set and the background area, this method calculates a marginality value (MAR), indicating the relative influence of each bioclimatic variable on the distribution of each species (see ENFA methods in Hirzel et al., 2002). For each bioclimatic variable, the MAR was regressed against each warming response trait. Where linear relationships indicated a significant and substantial influence of native distribution (MAR) on warming response (identified as those regressions with a significant $\mathrm{R}^{2} \geq$ 0.2 ), we investigated the bioclimatic variables and response traits by computing correlations and then running forward regression analyses to see if variables contributed independently to warming responses. Of the nineteen bioclimatic variables, we only display those with significant correlations in this study.

\section{Phylogenetic species tree}

Seedlings of the study species were grown in a nursery greenhouse at The Royal Botanic Gardens Melbourne to obtain DNA material for phylogenetic analysis. Leaf material of each species was removed and placed inside filter paper and into individually labelled plastic zip lock bags containing silica beads to remove moisture and allow the leaf samples to dry. The dried leaf material of each study species (20 mg) was used for DNA extraction, performed by the Australian Genome Research Facility (Waite Research Precinct, Hartley Grove, Urrbrae, South Australia). To target the nuclear region in our species we used the internal transcribed spacer (ITS) with primers from Field et al. (2006) and the external transcribed spacer (ETS) with primers from Bayer et al. (2002). The PCR protocol were the same for the nuclear regions using standard cycles; for one $10 \mu$ reaction, the contents were $\operatorname{MyTaq}^{\mathrm{TM}}(5 \mu)$, primer $\mathrm{x} 2(0.5 \mu)$, purified water $(3 \mu)$ and DNA template $(1 \mu)$. All samples were purified (using magnetic beads). To quantitate DNA, each sample was measured with a Qubit Fluorometer. Library preparation involved $100 \mathrm{ng}$ of template DNA diluted with purified water. An Agilent high sensitivity kit was used to produce DNA bioassays; to obtain sequences for our species tree, we used the next generation sequencing platform, Ion Torrent (Thermo Fisher Scientific, Waltham, 
Massachusetts, United States). A detailed library preparation using Ion Xpress ${ }^{\mathrm{TM}}$ can be found at lifetechnologies.com/support.

The raw Ion Torrent read.bam files were converted to fastq format using bedtools bamtofastq (Quinlan and Hall, 2010) before quality checking with FastQC (Andrews, 2010). Trimmomatic (Bolger et al., 2014) was then applied to trim low-quality bases with the settings "LEADING:18 TRAILING:18 SLIDINGWINDOW:10:18 MINLEN:50". Scripts from QIIME v1.8.0 (Caporaso et al., 2010) and custom scripts available at https://github.com/griffinp/amp_reseq were then used for downstream processing to return individual assembly files for each sample. Sequence assemblies were imported into Geneious v 6.1.4 (BioMatters Ltd, Auckland, New Zealand) and re-assembled de novo using custom settings ( $0 \%$ - majority). This assembly was examined manually and re-aligned as necessary before consensus sequences were made for each amplicon per individual. For each of the ITS and ETS gene alignments, appropriate codon position partitioning and nucleotide evolution models were chosen in PartitionFinder v1.1.1 (Lanfear et al., 2012) aceording to the best Bayesian information criteria (BIC value). An initial run of the Bayesian phylogenetic software BEAST v2.4.3 (Bouckaert et al., 2014) provided estimates of substitution rate and other nucleotide evolution model parameters used as non-estimated priors in a Starbeast2 run (Ogilvie et al., 2017) incorporating both genes. For ITS, these priors were: gamma time-reversible nucleotide evolution model with 4 gamma categories (gamma shape with a uniform distribution 0.17-0.37, initial value 0.27); empirical nucleotide frequency; substitution rate model TN93 (kappa1 0.8-2.2, initial value 1.5; kappa2 2.8-4.8, initial value 3.8) and base frequencies equal. For ETS, the estimates were: gamma time-reversible nucleotide evolution model (gamma shape with a uniform distribution, 0.26-0.66, initial value 0.46); nucleotide frequency estimated and individual nucleotide evolution rates set relative to CT (AC 0.39-0.79, initial value 0.59; AG 0.4-0.8, initial value 0.6; AT 0.29-0.49, initial value 0.39; CG 0.04-0.24, initial value 0.14 ; GT 0.06-0.2, initial value 0.13 ).

The Starbeast2 approach estimates an overall species tree along with individual gene trees for each marker. In this case, molecular clocks and gene trees were unlinked between markers. Ploidy was set to 2 for both regions; strict molecular clocks were used, and the ITS clock rate was held at 1 while the ETS clock rate was assigned a gamma distribution with size 2 and scale 20 (initial value 1). The species tree was modeled with a Yule model with speciation rate 
assigned a uniform distribution (0-10000, initial value 1) and species tree population size was set to 'constant', estimated during the run from a gamma distribution ( $\operatorname{size}=2$, scale $=10000)$ with population mean estimated from a uniform distribution $\left(0-1 \times 10^{6}\right.$, initial value $\left.1 \times 10^{4}\right)$. All other priors and operators were maintained at default settings. Starbeast2 was run for 50M generations, sampling trees every 5,000 generations. Traces were checked in Tracer v1.6 (Rambaut et al.,2014) to confirm all ESS values were $>200$, and the resulting species tree was visualized in DensiTree v2.0 (Bouckaert et al., 2014). A Maximum Clade Credibility tree was calculated in Tree Annotator (Bouckaert et al., 2014) after removing $20 \%$ of the run as burnin, and retaining median branch lengths.

\section{Phylogenetic signal analysis}

We followed the definition in Revell et al (2008) that phylogenetic signal is the statistical dependence among observations for species related by a phylogenetic tree, and investigated this with the R package phytools (Revell, 2012). We used $\log _{10}$-transformed trait data as used for the warming response analysis. Phylogenetic signal was computed using phylosig from the phytools R package (Revell, 2012) which estimates phylogenetic signal using two methods, Blomberg's K (Blomberg et al., 2003) and Pagel's $\lambda$ (Pagel, 1999) as well as carrying out hypothesis tests for significant phylogenetic signal and an estimate of phylogenetic signal with sampling error, as per Ives et al (2007).

\section{Results}

Survival

Seedling mortality levels were low. At the start of the experiment, there were 3,349 seedlings of which 1,675 were exposed to the soil warming treatment and 1,674 were exposed to ambient conditions (control). After the experiment concluded in late autumn 3,180 seedlings were alive (95\%), 1,606 in the warming treatment and 1,617 control plants. No significant association between survival and species and no species $\times$ warming-treatment interaction was observed at any census period throughout the experiment (data not presented) and therefore we did not explore survival further.

Is there a difference between species responses? 
The nested species term in the GLM (Table 2) significantly affected all traits (height, width, leaf length and root length), reflecting overall species differences in growth form. These effects remained significant after Bonferroni correction.

Is there a phylogenetic signal for warm temperature responses?

The two methods (Blomberg's $\mathrm{K}=1$ and Pagel's lambda $\lambda=0$ ) generally produced concordant results (Table 3 ). We did not detect a phylogenetic signal in our study species for warming responses in the above or below ground traits in spring or autumn. However, there was a phylogenetic signal for above ground measures of plant/leaf length unrelated to heating (see Table 2), indicating similar plant phenotypes in related species.

Are alpine endemics or specialists particularly susceptible to warming?

No alpine endemic or specialist species in this study showed an overall positive response to soil warming for all growth traits (height, width, leaf length and root length - see Fig. 1A - D respectively). When we analyzed the growth traits in a GLM (Table 2), only one significant overall treatment effect was detected (for root length $(\mathrm{P}<0.001)$ ), suggesting that while warming had no consistent above ground response on growth traits, alpine endemics tended to show a negative response below ground (Table 2). There was also a significant interaction between species and treatment for root length, reflecting species differences in warming responses (Table 2), which were variable (Fig. 1D). Two extreme cases involved an increase in root length of up to $70 \%$ compared to non-warmed controls (B. paludicola) and a decrease in root length of up to 77\% (B. tadgellii). For the above ground traits, the GLMs indicated species differences in autumn width and leaf length (both census points), highlighting species-specific warming responses. For width, these involved, for example, an increase of $27 \%$ over unheated plants in B. paludicola and a decrease of $18 \%$ in B. barkerae. For leaf length these involved, for example, an increase of $67 \%$ over non-warmed plants in B. stuartii and a decrease of $88 \%$ in B. barkerae.

In terms of species groupings, we found endemism (alpine endemics vs others) to have a significant negative effect on height in spring $(P=0.003)$, but not in autumn $(P=0.084)$, reflecting an initial group difference in delay in apical growth (Fig. 2A). On average, alpine endemics were $16 \%$ smaller than the other species in spring. For plant width, endemism was significant across seasons, however it was no longer significant after Bonferroni correction; 
alpine endemic species never grew as wide as the other species (Fig. 2B), resulting in a difference of $45 \%$ (effect size of $1.8 \mathrm{SD}$ ) in spring and $46 \%$ (1.5 SD) in autumn. Alpine endemism was marginally significant in spring for leaf length $(\mathrm{P}=0.023$, not significant after Bonferroni correction) but no effect was detected in autumn $(\mathrm{P}=0.489)$, again suggesting a delay in initial growth in the alpine endemic plants (Fig. 2C).

Despite these trait effects, there was no interaction between alpine endemism and the warming treatment for the above ground traits. However, alpine endemism had a marginally significant effect on root length $(\mathrm{P}=0.048$, not significant after correction), and importantly this trait showed a strong interaction with the warming treatment $(\mathrm{P}<0.001)$, reflecting a stronger negative effect of soil warming on the alpine endemics when compared to other species (Table 2). Therefore, poor root growth under warming in this study is particularly noticeable in the alpine endemics when compared to species that are not endemic to the alpine area (Fig. 2D). On average the alpine endemics showed a $19 \%(1.7 \times \mathrm{SD})$ reduction in root length from that of the other species. Fewer differences between groupings based on specialization were detected, with only marginally significant differences (not significant after correction) between the specialist and generalist groups (Table 2$)$ for plant height in spring $(P=0.043)$, and plant width in both spring $(\mathrm{P}=0.029)$ and autumn $(\mathrm{P}=0.020)$, and no treatment $\times$ specialization interaction effects apart from autumn width.

Do distribution variables show a phylogenetic signal?

We detected a strong phylogenetic signal for bioclimatic variable BIO15 that involves variability in annual precipitation (Fig.3). In contrast, we did not detect any strong phylogenetic signal for variables relating to temperature (e.g. BIO2).

Which distribution variables predict warming responses?

The above ground warming response was correlated with a separate set of distribution variables from those correlated with the below-growth response (root length) (Table 4). Using a forward regression model, the species MAR for the bioclimatic variables were used as predictors for autumn height (BIO2, 12, 13, 16 \& 19), width (BIO2 \& 8) and root length (BIO3, 4, \& 15) (see methods for explanation on variable choice). We found the bioclimatic variable $\mathrm{BIO} 2$, the mean diurnal temperature range (a measure of daily temperature fluctuation), was significantly 
associated with plant height $\left(\mathrm{R}^{2}=0.346, \mathrm{P}=0.008\right)$ and width $\left(\mathrm{R}^{2}=0.430, \mathrm{P}=0.002\right)($ Fig. $4 \mathrm{~A}$ \& B) whereas no additional variables were significant once this variable had been included in the equation. Precipitation seasonality (Fig. 4C), a measure of the variation in monthly precipitation totals over the course of the year (BIO15), was most closely associated with root length $\left(\mathrm{R}^{2}=\right.$ $0.367, \mathrm{P}=0.008)$.

\section{Discussion}

Overall, we found strong differences among species of Brachyscome in soil warming responses for root length and leaf length but not for plant height, and only weak differences for plant width. Although species differed in their overall above ground size, these differences generally did not translate into altered responses in the warmed versus control soil conditions. We also found little evidence that the climatic habitat of species influenced their warming response, although species from alpine areas did show a reduced response to soil warming.

We found seasonal differences in plant width and leaf length, highlighting species-specific warming responses. For example, under warming in autumn, we found increased growth (plant width) in a generalist species (Brachyscome paludicola) and decreased growth in a specialist species (Brachyscome barkerae). We also found an increase in leaf length under warming in a generalist species (Brachyscome stuartii) and a decrease in a specialist species (Brachyscome barkerae).

We were interested in how the wild-collected Brachyscome multifida used in this study would perform in cultivation, given that B. multifida is a popular ornamental plant. The wild form we tested performed well, showing a strong, positive warming response in shoot growth and negligible effect of warming on root growth. Our approach in this study points to useful species for future cultivation, particularly those providing similar results to Brachyscome multifida, such as B. stuartii and B. rigidula. As climate change affects horticultural practices worldwide (Dixon et al., 2014), impacts on garden plants (as opposed to impacts on those in the wild) can be buffered by cultivation, plant selection and garden practices (Bisgove and Hadley, 2002).

It was expected generalist species known for their larger extant range size would show less negative impacts of warming than specialists ( Brown, 1995, Thuiller et al., 2005). This appeared to be the case for root responses to soil warming in Brachyscome tesquorum, B. paludicola, B. 
dentata, B. multifida, and B. stuartii and two species whose geographic range size includes alpine habitats, B. rigidula and B. aculeata. All these species tend to be exposed to high temperatures in some of their natural environments, suggesting a positive niche breadth-range size association (Slatyer et al., 2013). In contrast, endemic and narrowly distributed species, such as Brachyscome tadgellii and B. stolonifera, may perform particularly poorly under warming conditions. However, this pattern was more closely tied to alpine endemism rather than habitat specialization status in general. However, we understand these findings must be viewed within an experimental context as specific conditions including soil characteristics and water availability would vary considerably across the range of this study group.

Alpine species tend to exhibit relatively slow root growth in colder sites but exhibit similar rates of above-ground growth in cold as in warm sites (Nagelmüller et al., 2016). The Nagelmüller et al. (2016) study indicated alpine soil temperatures at $5^{\circ} \mathrm{C}$ could facilitate fully developed root systems, whereas temperatures exceeding $10^{\circ} \mathrm{C}$ do not provide any additional stimulation in root growth. This likely reflects the intrinsic nature of alpine systems that can support these temperature thresholds (Körner, 2003, McDougall and Walsh, 2007). Root growth can also be affected by available water and nutrients within the soil profile, as well as the combined effect of increased soil temperatures and elevated $\mathrm{CO}_{2}$, although these responses are often species specific (Madhu and Hatfield, 2013). Soil moisture is likely to be an important issue in alpine environments in the future given that drought affects Australian alpine plants (Griffin and Hoffmann, 2012) and drought conditions are expected to become more intense and more frequent in alpine habitats (Grose, 2015).

While the ecological attributes showed some association with warming responses, there was a negligible effect of phylogenetic history on warming responses. However, a moderate phylogenetic signal was found for above ground phenotypic traits (height, width and leaf length) irrespective of warming treatment. There was a strong phylogenetic signature for the bioclimatic variable with annual variability in precipitation (BIO15), suggesting that closely related species tend to occur in areas with similar annual variability in precipitation, reflecting similar trait values for the alpine endemics and for four related generalists.

The difference in trait values may reflect the fact that all the alpine endemics ended up clustered on the species tree (Fig. S2), but the Pembertonia species, which also had poor root growth, was 
unrelated to this group. The clustering of the alpine species points to phylogenetic conservatism, which as noted in Prinzing (2001) may reflect environmental opportunities of ancestral species during diversification. It may also reflect the narrow phylogenetic range of species considered here, unlike in the study by Thuiller et al. (2011) who considered a very broad range incorporating phylogenies of plant, bird and mammal assemblages across Europe. Perhaps recent species divergence in Brachyscome is not strongly driven by climate.

When we investigated the relationship between bioclimatic variables associated with the species' natural distribution and the species warming responses, we found the above ground plant growth (width and height) was positively associated with diurnal temperature (BIO2), whereas root length was negatively associated with annual variability in precipitation (BIO15). These plant traits therefore appear to be associated with distinct sets of environmental conditions. The reasons for these distinct associations are not entirely clear; however, species that come from variable thermal conditions might be expected to grow well under warming, while species from environments with variable precipitation might be expected to maintain long roots regardless of warming (Knapp and Smith 2001).

In conclusion, we show here that Brachyscome species differ in their response to soil warming with respect to root length and leaf length, but not height, despite inherent size differences among the species. While plant size shows moderate phylogenetic signature, the soil warming responses do not. Root and leaf warming responses tended to be more strongly positive in species from outside the alpine area. It is worth noting that in these experiments we have only assessed soil warming in a common garden, and not in the natural habitat occupied by each species (c.f. Hirst et al., 2016) nor by considering 'in field' experimental tools (for example infra-red lamps). This means that we cannot directly assess the threat posed by warming in the natural habitat of each species, but only their inherent responses under one set of environmental conditions. We have also used one approach to examining warming by focusing on soil temperature, whereas other researchers have used infra-red lamps (Hovenden et al., 2017) or plastic sheets (Wahren et al., 2013) to heat the above ground environment. These approaches have different advantages and limitations; for instance, passive warming via sheets results in changes in wind exposure, which may affect plant growth and invertebrate activity (Hoffmann et al., 2010). We have also not assessed transgenerational effects that might influence plant 
463 responses (Jablonka and Raz, 2009). Nevertheless, in the current context, all species are clearly 464 capable of persisting in warmer soil but some species show weaker growth responses that may 465 reduce their fitness into the future. Retesting at higher soil temperatures and with different 466 methodologies provide next steps in exploring potential effects of warming on species 467 persistence and growth.

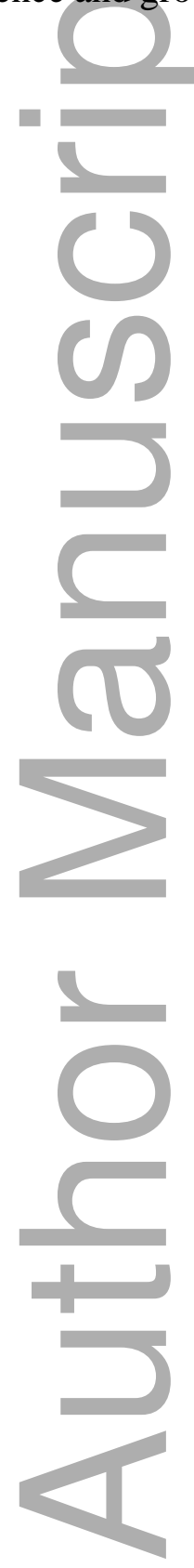




\section{Supplementary data}

Table S1: The Brachyscome study species, the Australian Seed bank sources that donated seed, and the corresponding species accession number. Table S2: Total number of individual plants of each of the 19 study species tested for warming responses. Figure S1: Brachyscome study species distributions showing occurrence points in red within Australia. Figure S2: The Brachyscome study species tree showing the position of taxa used in this study as an unrooted maximum clade credibility (MCC) tree created in Starbeast2 (Ogilvie et al., 2017).

\section{Acknowledgements}

This research was funded through an Australian Postgraduate Award and a Holsworth Wildlife Research Endowment (MJH). We thank Rodger Elliot, the Garden Ambassadors, and the Growing Friends of the Cranbourne Botanic Gardens for their ongoing support and enthusiasm for the Royal Botanic Gardens Cranbourne (RBGC) outdoor research garden. We thank our colleagues of the Royal Botanic Gardens Victoria and the Hoffmann Lab (Bio 21), and members of the Australian Seedbank Partnership. We thank Michael Nash and Warren Worboys for their assistance in setting up the RBGC plots, and to Bronwyn Swartz for site maintenance.

\section{References}

Andrews S. 2010. FastQC: a quality control tool for high throughput sequence data. Available online at: http://www.bioinformatics.babraham.ac.uk/projects/fastqc.

Bayer RJ, Greber DG, Bagnall NH. 2002. Phylogeny of Australian Gnaphalieae (Asteraceae) based on chloroplast and nuclear sequences, the $\operatorname{trnL}$ intron, $\operatorname{trnL} / \operatorname{trnF}$ intergenic spacer, matK, and ETS. Systematic Botany, 27: 801-814.

Becklin KM, Anderson JT, Gerhart LM, Wadgymar SM, Wessinger CA, Ward JK. 2016. Examining plant physiological responses to climate change through an evolutionary lens. Plant Physiology, 172: 635-649. 
Bisgrove R, Hadley P. 2002. Gardening in the global greenhouse: the impacts of climate change on gardens in the UK. Technical Report, UKCIP, Oxford. 1 - 134.

Bita CE, Gerats T. 2013. Plant tolerance to high temperature in a changing environment: scientific fundamentals and production of heat stress-tolerant crops. Frontiers in Plant Science, 4: 273.doi:10.3389/fpls.2013.00273.

Blomberg SP, Garland T, Ives AR. 2003. Testing for phylogenetic signal in comparative data: behavioral traits are more labile. Evolution, 57: 717-745.

Bolger AM, Lohse M, Usadel B. 2014. Trimmomatic: a flexible trimmer for Illumina sequence data. Bioinformatics, 30: 2114-2120.

Bouckaert R, Heled J, Kühnert D, Vaughan T, Wu C-H, Xie D, Suchard MA, Rambaut A, Drummond AJ. 2014. BEAST 2: A software platform for bayesian evolutionary analysis. PLOS Computational Biology, 10: e1003537. doi:10.1371/journal.pcbi.1003537.

Brown JH. 1995. Macroecology. The University of Chicago Press, Chicago, 270pp.

Calenge C. 2006. The package adehabitat for the R software: a tool for the analysis of space and habitat use by animals. Ecological Modelling, 197: 516-519.

Caporaso JG, et al. 2010. QIIME allows analysis of high-throughput community sequencing data. Nature Methods, 7: 335-336.

Chesson P, Gebauer RLE, Schwinning S, Huntly N, Wiegand K, Ernest MSK, Sher A, Novoplansky A, Weltzin JF. 2004. Resource pulses, species interactions, and diversity maintenance in arid and semi-arid environments. Oecologia, 141: 236-253.

Cornelissen T. 2011. Climate change and its effects on terrestrial insects and herbivory patterns. Neotropical Entomology, 40: 155-163.

Cowles J, Boldgiv B, Liancourt P, Petraitis PS, Casper BB. 2018. Effects of increased temperature on plant communities depend on landscape location and precipatation. Ecology and Evolution, 8: 5267-5278.

Dixon GR, Collier RH, Bhattacharya I. 2014. An assessment of the effects of climate change on horticulture. In: Dixon GR, Aldous DE, eds. Horticulture: plants for people and places. Dordrecht: Springer. 
Field B, Houben A, Timmis J, Leach C. 2006. Internal transcribed spacer sequence analyses indicate cytoevolutionary patterns within Brachycome Cass.(Asteraceae). Plant Systematics and Evolution, 259: 39-51.

Forrest JRK. 2015. Plant-pollinator interactions and phenological change: what can we learn about climate impacts from experiments and observations? Oikos, 124: 4-13.

Gratani L. 2014. Plant phenotypic plasticity in response to environmental factors. Advances in Botany, 2014: 1-17. http://dx.doi.org/10.1155/2014/208747.

Griffin PC, Hofmann AA. 2012. Mortality of Australian alpine grasses (Poa spp.) after drought: species differences and ecological patterns. Journal of Plant Ecology, 5: 121-133. https://doi.org/10.1093/jpe/rtr010.

Grose M et al. 2015. Southern slopes cluster report, climate change in Australia projections for Australia's natural resource management regions:cluster resports, eds. Ekström M., et al., CSIRO and Bureau of Meterology. 1 - 65.

Hatfield JL, Prueger JH. 2015. Temperature extremes: Effect on plant growth and development. Weather and Climate Extremes, 10: 4-10. Part A.

Hirst MJ. 2012. Native daisies add versatility. Australian Horticulture, 109: 8-8

Hirst MJ, Sexton JP, Hoffmann AA. 2016. Extensive variation, but not local adaptation in an Australian alpine daisy. Ecology and Evolution, 6: 5459-5472.

Hirzel AH, Hausser J, Chessel D, Perrin N. 2002. Ecological-niche factor analysis: how to compute habitat-suitability maps without absence data? Ecology, 83: 2027-2036.

Hoffmann AA, et al. 2019. Impacts of recent climate change on terrestrial flora and fauna: Some emerging Australian examples. Austral Ecology, 44: 3 - 27. doi:10.1111/aec.12674.

Hoffmann AA, Camac JS, Williams RJ, Papst W, Jarrad FC, Wahren CH. 2010. Phenological changes in six Australian subalpine plants in response to experimental warming and year-to-year variation. Journal of Ecology, 98: 927 - 937.

Hovenden MJ, Newton PCD, Porter M. 2017. Elevated CO2 and warming effects on grassland plant mortality are determined by timing of rainfall. Annals of Botany, 119: 1225-1233. doi:10.1093/aob/mcx006.

Hughes TP, et al. 2017. Global warming and recurrent mass bleaching of corals. Nature, $\mathbf{5 4 3}$ : 373-377. doi:10.1038/nature21707. 
IPCC 2013. Climate Change 2013: The Physical Science Basis. Contribution of Working Group I to the Fifth Assessment Report of the Intergovernmental Panel on Climate Change [Stocker, T.F., D. Qin, G.-K. Plattner, M. Tignor, S.K. Allen, J. Boschung, A. Nauels, Y. Xia, V. Bex and P.M. Midgley(eds.)]. Cambridge University Press, Cambridge, United Kingdom and New York, NY, USA, 1535 pp. https://doi.org/10.1017/CBO9781107415324.

Ives AR, Midford PE, Garland JT. 2007. Within-species variation and measurement error in phylogenetic comparative methods. Systematic Biology, 56: 252-270.

Jablonka E, Raz G. 2009. Transgenerational epigenetic inheritance: prevalence, mechanisms, and implications for the study of heredity and evolution. The Quarterly Review of Biology, 84: 131-176.

Kimball BA, Alonso-Rodriguez AM, Cavaleri MA, Reed SC, González G, Wood TE. 2017. Infrared heater system for warming tropical forest understory plants and soils. Ecology and Evolution, 8: 1932-1944. https://doi.org/10.1002/ece3.3780.

Knapp AK, Smith MD. 2001. Variation among biomes in temporal dynamics of aboveground primary production. Science, 291: 481-484. doi:10.1126/science.291.5503.481.

Körner C. 2003. Alpine plant life: functional plant ecology of high mountain ecosystems. Berlin, Heidelberg, New York: Springer-Verlag.

Lanfear R, Calcott B, Ho SY, Guindon S. 2012. PartitionFinder: combined selection of partitioning schemes and substitution models for phylogenetic analyses. Molecular Biology and Evolution, 29: 1695-1701.

Madhu M, Hatfield JL. 2013. Dynamics of plant root growth under increased atmospheric carbon dioxide. Journal of Agronomy, 105: 657-669. doi:10.2134/agronj2013.0018.

Manzanedo RD, Schanz FR, Fischer M, Allan E 2018. Fagus sylvatica seedlings show provenance differentiation rather than adapation to soil in a transplant experiment. BMC ecology, 18: 42. doi: 10.1186/s12898-018-0197-5.

McDougall KL, Walsh NG. 2007. Treeless vegetation of the Australian Alps. Cunninghamia, 10: $1-57$.

Moni C, Silvennoinen H, Kimball BA, Fjelldal E, Brenden M, Burud I, Flø A, Rasse DP. 2019. Controlled infrared heating of an artic medow:challenge in the vegetation establishment stage. BMC ecology, 15: https://doi.org/10.1186/s13007-019-0387-y. 
Nagelmüller S, Hiltbrunner E, Körner C. 2016. Critically low soil temperatures for root growth and root morphology in three alpine plant species. Alpine Botany, 126: 11-21.

Ogilvie HA, Bouckaert RR, Drummond AJ. 2017. StarBEAST2 brings faster species tree inference and accurate estimates of substitution rates. Molecular Biology and Evolution. 34: 2101-2114. doi: 10.1093/molbev/msx126.

Pagel M. 1999. Inferring the historical patterns of biological evolution. Nature, 401: 877-884.

Pärtel M, Laanisto L, Zobel M. 2007. Contrasting plant productivity-diversity relationships across latitude: the role of evolutionary history. Ecology, 88: 1091-1097.

Pearson RG, Phillips SJ, Loranty MM, Beck PSA, Damoulas T, Knight SJ, Goetz SJ. 2013. Shifts in arctic vegetation and associated feedbacks under climate change. Nature Climate Change, 3: 673-677.

Pickering CM, Venn SE. 2013. Increasing the resilience of the Australian alpine flora to climate change and associated threats: a plant functional traits approach. National Climate Change Adaptation Research Facility. Gold Coast, 84pp.

Prinzing A. 2001. The niche of higher plants: evidence for phylogenetic conservatism. Proceedings of the Royal Society of London. Series B: Biological Sciences, 268: 23832389

Pollock BR. 2017. Latitudinal change in the distribution of luderick Girella tricuspidata (Pisces: Girellidae) associated with increasing coastal water temperature in eastern Australia. Marine and Freshwater Research, 68: 1187-1192.

Quinlan AR, Hall IM. 2010. BEDTools: a flexible suite of utilities for comparing genomic features. Bioinformatics, 26: 841-842.

Rambaut A, Suchard M, Xie D, Drummond A. 2014. Tracer v1. 6, Available from http://beast.bio.ed.ac.uk/Tracer.

Revell LJ. 2012. Phytools: an R package for phylogenetic comparative biology (and other things). Methods in Ecology and Evolution, 3: 217-223.

Revell LJ, Harmon LJ, Collar DC. 2008. Phylogenetic signal, evolutionary process, and rate. Systematic Biology, 57: 591-601.

Rustad LE, et at. 2001. A meta-analysis of the response of soil respiration, net nitrogen mineralization, and aboveground plant growth to experimental ecosystem warming. Oecologia, 126: 543-562. doi:10.1007/s004420000544. 
Salkin E, Thomlinson G, Armstrong B, Courtney B, Schaumann M. 1995. Australian brachyscomes. Melbourne, Victoria, The Australian Daisy Study Group.

Shaver GR, Canadell J, Chapin Iii F, Gurevitch J, Harte J, Henry G, Ineson P, Jonasson S,

Melillo J, Pitelka L. 2000. Global warming and terrestrial ecosystems: a conceptual framework for analysis. Bioscience, 50: 871-882.

Short PS. 2004. Three new genera of Australian Astereae (Asteraceae). Muelleria, 20: 53 -66.

Short PS. 2014. A taxonomic review of Brachyscome Cass. s. lat.(Asteraceae: Astereae), including descriptions of a new genus, Roebuckia, new species and new infraspecific taxa. Journal of the Adelaide Botanic Gardens, 28: 1-219.

Slatyer RA, Hirst MJ, Sexton JP. 2013. Niche breadth predicts geographical range size: a general ecological pattern. Ecology Letters, 16: 1104-1114.

Sokal R, Rohlf F. 2012. Biometry: the principles and practice of statistics in biological research. $4^{\text {th }}$ ed. New York: W.H. Freeman.

Thuiller W, Lavergne S, Roquet C, Boulangeat I, Lafourcade B, Araujo MB. 2011.

Consequences of climate change on the tree of life in Europe. Nature, 470: 531-534.

Thuiller W, Lavorel S, Araújo MB. 2005. Niche properties and geographical extent as predictors of species sensitivity to climate change. Global Ecology and Biogeography, 14: $347-357$.

Tilman D, Wedin D, Knops J. 1996. Productivity and sustainability influenced by biodiversity in grassland ecosystems. Nature, 379: 718-720.

Wahren CH, Camac JS, Jarrad FC, Williams RJ, Papst WA, Hoffmann AA. 2013. Experimental warming and long-term vegetation dynamics in an alpine heathland. Australian Journal of Botany, 61: 36-51.

Willis CG, Ruhfel B, Primack RB, Miller-Rushing AJ, Davis CC. 2008. Phylogenetic patterns of species loss in Thoreau's woods are driven by climate change. Proceedings of the National Academy of Sciences of the United States of America, 105: 17029-17033. 
Table 1. The 19 perennial Brachyscome species in this study. Pembertonia latisquamea was previously considered a member of the genus Brachyscome (Short, 2004). State/Territory refers to broad distribution within Australia; TAS = Tasmania; VIC = Victoria; SA = South Australia; NSW = New South Wales; QLD = Queensland; NT = Northern Territory; and WA = Western Australia. IBRA refers to the Interim Biogeographic Regionalisation for Australia. Taxon group refers to the 14 informal morphological groupings defined by Short (2014). Alpine occupancy (yes/no) refers to whether a species range includes the alpine zone. Species that are only distributed in the Australian Alps were classified as alpine endemics. The * symbol indicates species that have previously been identified for their ornamental value. Threat status of species: B. barkerae and B. foliosa, are listed as vulnerable in Victoria; B. obovata, B. salkiniae, and B. tadgellii are listed as rare in Victoria, see https://vicflora.rbg.vic.gov.au/; B. stolonifera is listed as rare in New South Wales, see http://plantnet.rbgsyd.nsw.gov.au/.

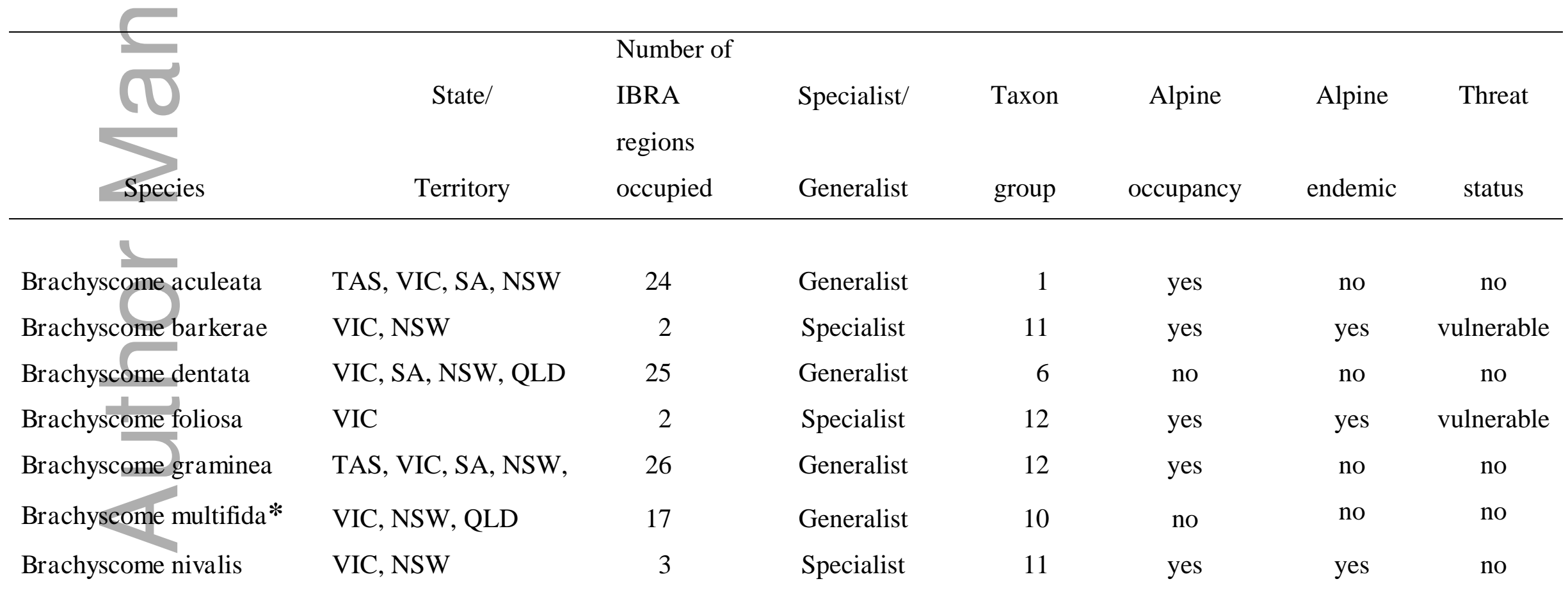


Environmental warming responses of Brachyscome

\begin{tabular}{|c|c|c|c|c|c|c|c|}
\hline Brachyscome obovata & VIC, NSW & 4 & Specialist & 12 & yes & no & rare \\
\hline Brachyscome paludicola & VIC, SA, NSW & 14 & Generalist & 2 & no & no & no \\
\hline Brachyscome radicans & TAS, VIC, NSW & 9 & Generalist & 11 & yes & no & no \\
\hline Brachyscome rigidula & TAS, VIC, NSW, QLD & 13 & Generalist & 4 & yes & no & no \\
\hline Brachyscome salkiniae & VIC, NSW & 2 & Specialist & 13 & no & no & rare \\
\hline Brachyscome scapigera & VIC, NSW, QLD & 10 & Generalist & 12 & yes & no & no \\
\hline Brachyscome spathulata & TAS, VIC, NSW & 21 & Generalist & 1 & yes & no & no \\
\hline Brachyscome stolonifera & NSW & 1 & Specialist & 11 & yes & yes & rare \\
\hline Brachyscome stuartii & NSW, QLD & 7 & Generalist & 10 & no & no & no \\
\hline Brachyscome tadgellii & VIC & 1 & Specialist & 11 & yes & yes & rare \\
\hline Brachyscome tesquorum & WA, SA, NT & 11 & Generalist & 4 & no & no & no \\
\hline Pembertonia latisquamea & WA & 3 & Specialist & 15 & no & no & no \\
\hline
\end{tabular}


Table 2. General linear model results for traits (height, width, leaf length and root length) in the common garden. $\mathrm{df}=\mathrm{degrees}$ of freedom; $M S=$ mean squares. endemic (E) represents whether species were split into two groups based on endemism (alpine endemic vs others), specialist (S) represents whether species were split into groups based on specialisation (specialist vs generalist). Bold text indicates a significant effect after Bonferroni correction.

\begin{tabular}{|c|c|c|c|c|c|c|c|}
\hline Trait & Season & Model & $\mathrm{df}(\mathrm{E} / \mathrm{S})$ & MS (E) & $\mathrm{P}(\mathrm{E})$ & $\mathrm{MS}(\mathrm{S})$ & $\mathrm{P}(\mathrm{S})$ \\
\hline \multirow[t]{12}{*}{ Height } & \multirow[t]{6}{*}{ Spring } & Endemic (E)/Specialist (S) & 1 & 16.296 & 0.003 & 4.635 & 0.043 \\
\hline & & Species (E/S) & 17 & 4.530 & $<0.001$ & 4.256 & $<0.001$ \\
\hline & & Treatment & 1 & 0.081 & 0.236 & 0.042 & 0.396 \\
\hline & & $\mathrm{E} / \mathrm{S} \times$ Treatment & 1 & 0.075 & 0.254 & 0.014 & 0.627 \\
\hline & & Species $(E / S) \times$ Treatment & 17 & 0.054 & 0.548 & 0.054 & 0.548 \\
\hline & & Error & 3137 & 0.053 & & 0.053 & \\
\hline & \multirow[t]{6}{*}{ Autumn } & Endemic (E)/Specialist (S) & 1 & 9.174 & 0.084 & 5.028 & 0.170 \\
\hline & & Species (E/S) & 17 & 9.328 & $<0.001$ & 9.478 & $<0.001$ \\
\hline & & Treatment & 1 & 0.232 & 0.116 & 0.346 & 0.055 \\
\hline & & $\mathrm{E} / \mathrm{S} \times$ Treatment & 1 & 0.192 & 0.152 & 0.147 & 0.210 \\
\hline & & Species $(E / S) \times$ Treatment & 17 & 0.106 & 0.241 & 0.109 & 0.214 \\
\hline & & Error & 3143 & 0.087 & & 0.087 & \\
\hline \multirow[t]{5}{*}{ Width } & \multirow[t]{5}{*}{ Spring } & Endemic (E)/Specialist (S) & 1 & 13.088 & 0.002 & 5.716 & 0.029 \\
\hline & & Species (E/S) & 17 & 3.182 & $<0.001$ & 3.460 & $<0.001$ \\
\hline & & Treatment & 1 & 0.003 & 0.817 & 0.021 & 0.519 \\
\hline & & $\mathrm{E} / \mathrm{S} \times$ Treatment & 1 & 0.048 & 0.330 & 0.001 & 0.881 \\
\hline & & Species $(E / S) \times$ Treatment & 17 & 0.055 & 0.321 & 0.055 & 0.312 \\
\hline
\end{tabular}

This article is protected by copyright. All rights reserved 


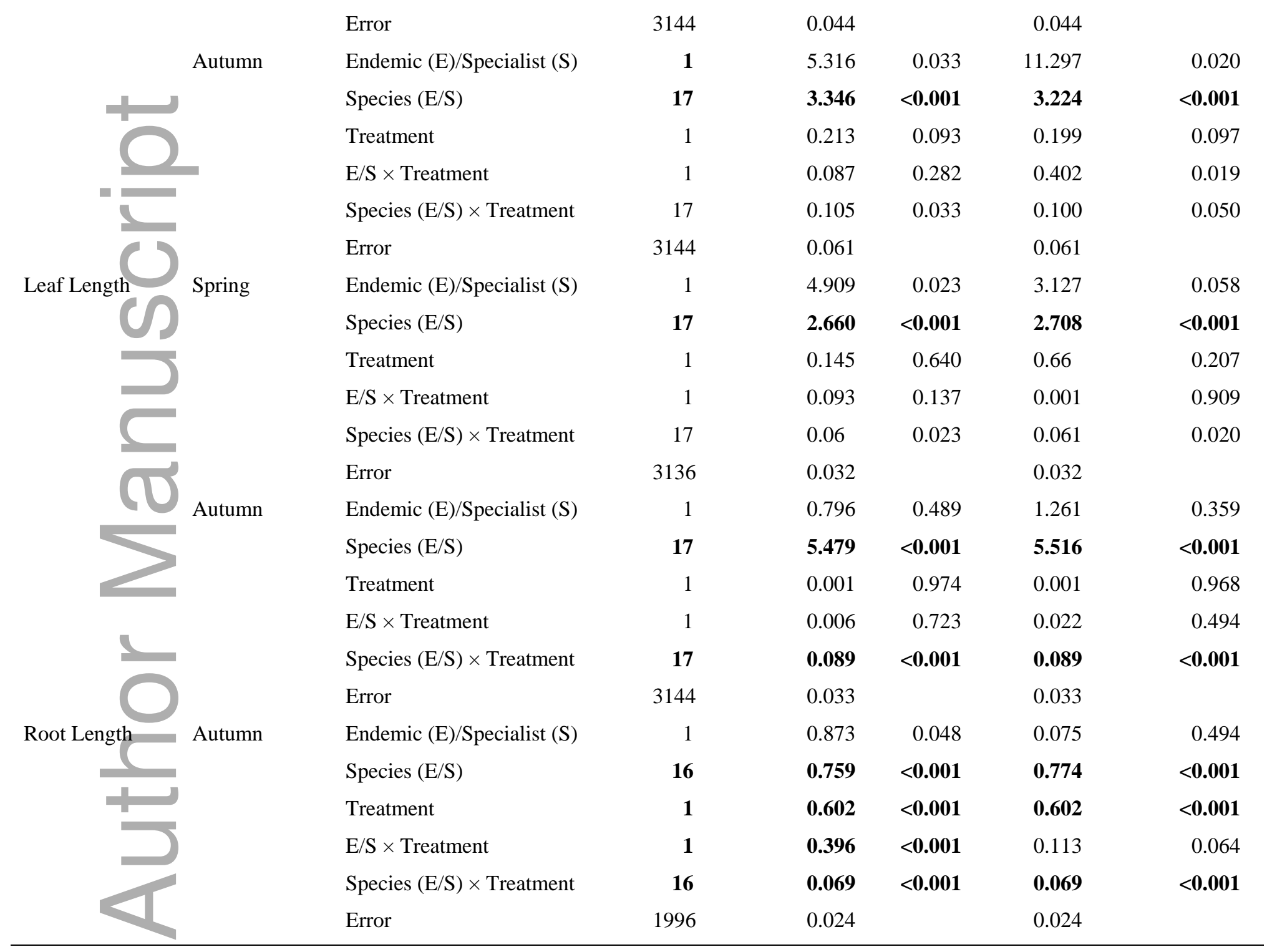

This article is protected by copyright. All rights reserved 
Table 3. Phylogenetic signal detected for bioclimatic variables and plant phenotypic traits. Phylogenetic signal was assessed as Blomberg's K (P values from 1000 randomizations) and Pagel's Lambda (ML estimation likelihood ratio test against null hypothesis that $\lambda=0$ ). Bold text indicates moderate to strong phylogenetic signal. $* \mathrm{P}<0.05=$ weak signal, $* * \mathrm{P}<0.01=$ moderate signal, $* * * \mathrm{P}<0.001=$ strong signal.

\begin{tabular}{|c|c|c|c|c|c|c|}
\hline \multirow[t]{2}{*}{ Trait } & \multirow[t]{2}{*}{ Trait description } & \multicolumn{2}{|c|}{ Blomberg's K } & \multicolumn{2}{|c|}{ Pagel's Lambda } & \multirow[b]{2}{*}{ Overall strength } \\
\hline & & $\mathrm{K}$ & $\mathrm{P}$ & $\lambda$ & $P$ & \\
\hline \multirow[t]{4}{*}{ Plant height } & Spring & 0.817 & 0.021 & 0.969 & 0.015 & moderate signal \\
\hline & Spring (warming response) & 0.023 & 0.984 & 6.659 & 1 & no signal \\
\hline & Autumn & 0.822 & 0.031 & 7.277 & 0.100 & no signal \\
\hline & Autumn (warming response) & 0.133 & 0.676 & 6.594 & 1 & no signal \\
\hline \multirow[t]{4}{*}{ Plant width } & Spring & 0.858 & 0.010 & 0.980 & 0.009 & moderate signal \\
\hline & Spring (warming response) & 0.039 & 0.957 & 6.659 & 1 & no signal \\
\hline & Autumn & 1 & 0.005 & 1 & 0.003 & moderate signal \\
\hline & Autumn (warming response) & 0.092 & 0.795 & 6.659 & 1 & no signal \\
\hline \multirow[t]{4}{*}{ Leaf length } & Spring & 0.699 & 0.036 & 0.942 & 0.023 & moderate signal \\
\hline & Spring (warming response) & 0.068 & 0.847 & 6.659 & 1 & no signal \\
\hline & Autumn & 0.807 & 0.019 & 0.954 & 0.023 & moderate signal \\
\hline & Autumn (warming response) & 0.021 & 0.989 & 6.659 & 1 & no signal \\
\hline \multirow[t]{2}{*}{ Root length } & Autumn & 0.042 & 0.938 & 6.669 & 1 & no signal \\
\hline & Autumn (warming response) & 0.118 & 0.776 & 0.512 & 0.332 & no signal \\
\hline Bioclimatic variable & $\mathrm{BIO} 2$ & 0.513 & 0.238 & 6.659 & 1 & no signal \\
\hline I & BIO15 & 1.658 & 0.001 & 1 & $<0.001$ & strong signal \\
\hline
\end{tabular}

This article is protected by copyright. All rights reserved 
Table 4. Bivariate correlations between the autumn warming responses (in height, width and root length) and 9 bioclimatic variables significant at the $\mathrm{P}<0.01$ level $(* *)$ or $\mathrm{P}<0.05$ level $(*)$ (two tailed). Only significant correlations are shown.

\begin{tabular}{|c|c|c|c|c|c|c|c|c|c|}
\hline \multirow[b]{2}{*}{ Trait } & \multicolumn{9}{|c|}{ Bioclimatic variables } \\
\hline & $\mathrm{BIO} 2$ & $\mathrm{BIO} 3$ & $\mathrm{BIO} 4$ & $\mathrm{BIO} 8$ & $\mathrm{BIO} 12$ & BIO13 & BIO15 & BIO16 & BIO19 \\
\hline Height & $.588 * *$ & & & & $-0.486 *$ & $-0.536 *$ & & $-0.521 *$ & $-0.524 *$ \\
\hline Width & $0.656 * *$ & & & $0.499 *$ & & & & & \\
\hline Root & & $0.569 *$ & $-0.553 *$ & & & & $-0.606 * *$ & & \\
\hline
\end{tabular}

BIO2: mean diurnal temperature range (mean of monthly (max temp -min temp)). BIO3: Isothermality (BIO2/BIO7 (temperature annual range) $\times 100)$ ). BIO4: Temperature seasonality (standard deviation $\times 100)$. BIO8: Mean temperature of the wettest quarter $(1 / 4$ of year). BIO12: Annual precipitation. BIO13: Precipitation of the wettest month. BIO15: Precipitation seasonality (coefficient of variation). BIO16: Precipitation of the wettest quarter (1/4 of year). BIO19: Precipitation of the coldest quarter (1/4 of year). 
Figure Legend

Figure 1. Warming responses of the study species for each growth trait $\left(\log _{10}\right)$ : (A) plant height (B) plant width (C) leaf length and (D) root growth. Brachyscome tesquorum is not included in Fig. 1D as root length was not measured for this species. $(\mathrm{G})=$ generalist; $(\mathrm{S})=$ specialist; $(\mathrm{S} \& \mathrm{E})$ $=$ specialist and alpine endemic; $*$ = previously identified as having ornamental value.

Figure 2. Box plots for (A) height, (B) width, (C) leaf length, and (D) root length for the alpine endemics versus all other species (others) in spring and autumn with warming and without warming. The length of each box is the interquartile range containing $50 \%$ of the data points. The solid black line represents medians, error bars represent ranges. Outliers (shown as open points) are values extending $1.5 \mathrm{x}$ interquartile range. Pembertonia latisquamea was not included in the dataset for root length.

Figure 3. Phylogenetic patterns among the 19 Brachyscome species in which a strong phylogenetic signal was detected in the precipitation seasonality; (bioclimatic variable BIO15).

Figure 4. Selected scatterplots investigating the relationship between bioclimatic variables (MAR) and trait responses; (A): $\mathrm{x}$ axis is the mean diurnal temperature range (BIO2) and y axis plant height $(\log )$; (B) $\mathrm{x}$ axis is BIO2 and y axis is plant width $(\log )$; (C) $\mathrm{x}$ axis is the precipitation seasonality (BIO15) and y axis is root length (log). Dashed lines indicate linear regressions.

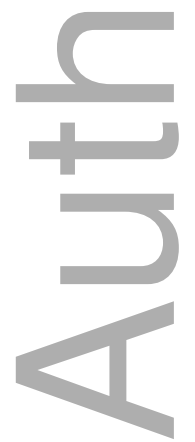


A
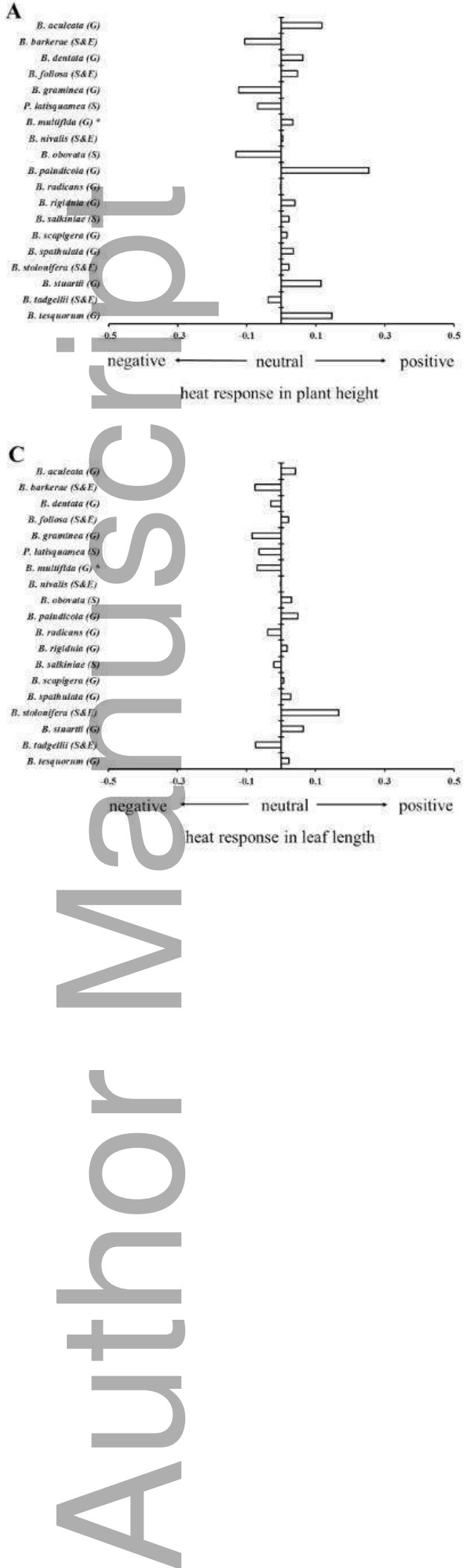

B

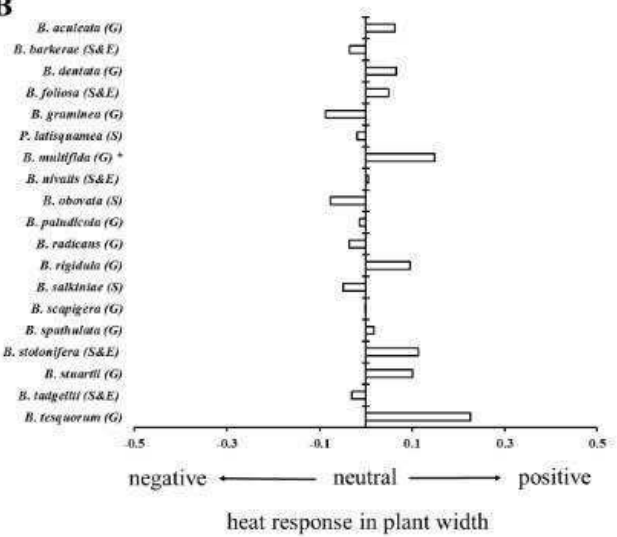

D

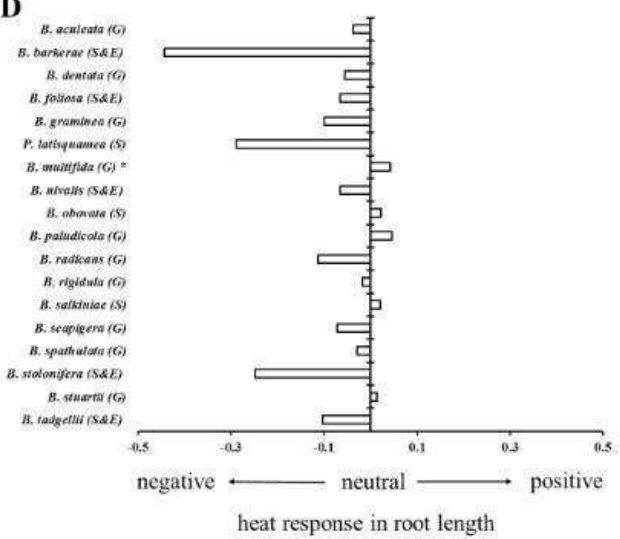


A
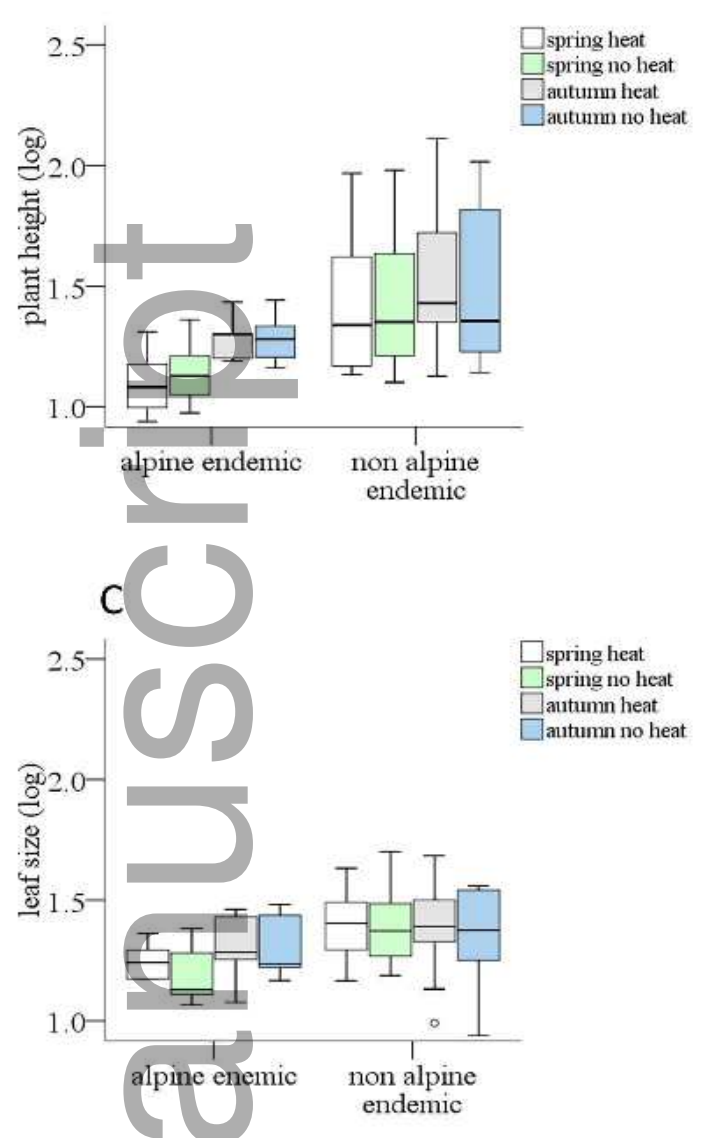

B

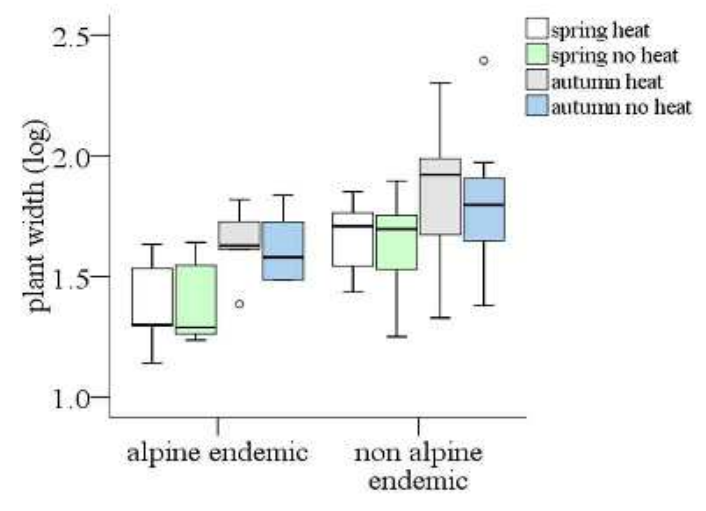

D

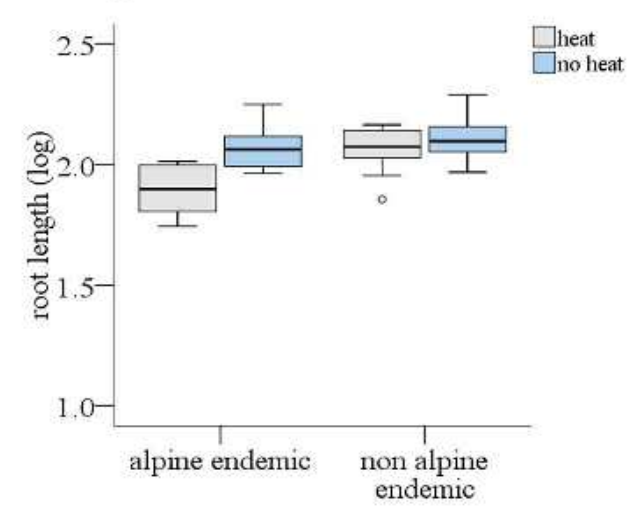




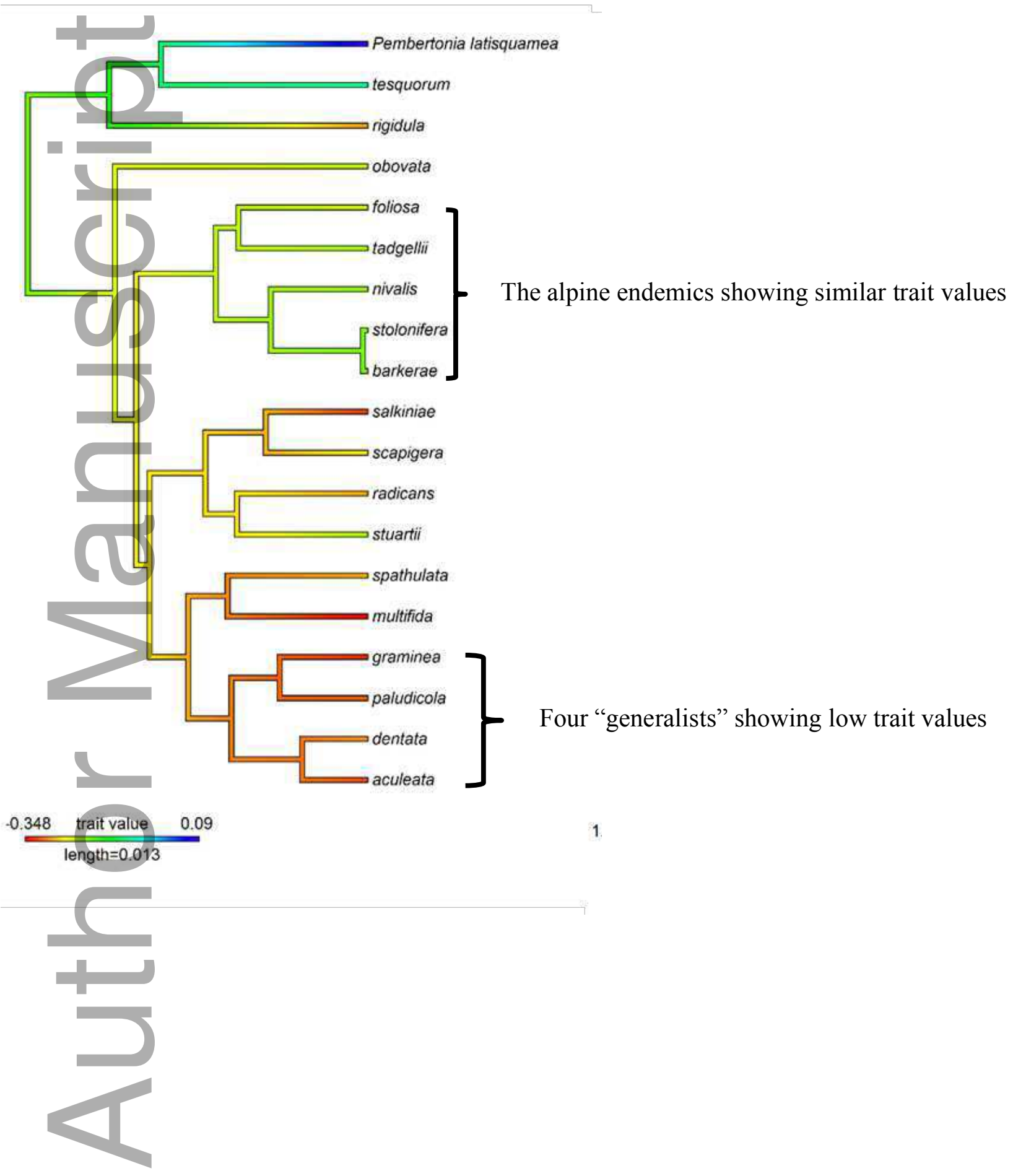

This article is protected by copyright. All rights reserved 
A
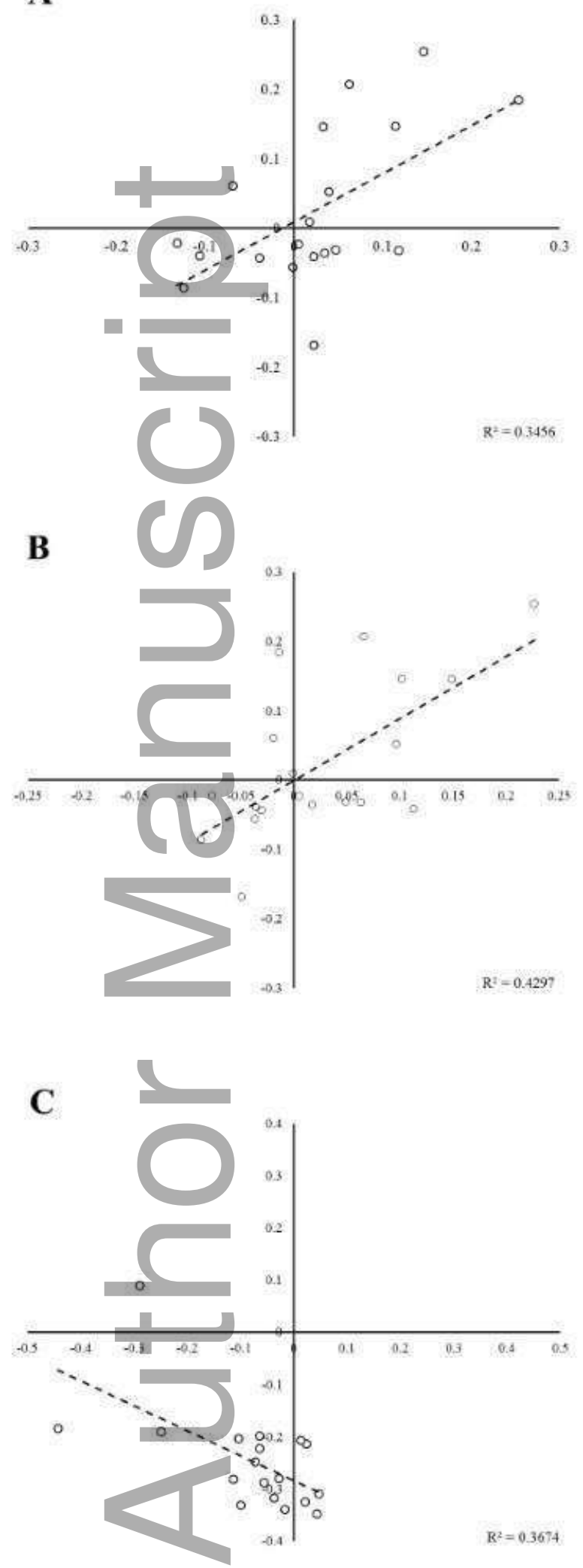

This article is protected by copyright. All rights reserved 


\section{University Library}

\section{- M M N E R VA A gateway to Melbourne's research publications}

Minerva Access is the Institutional Repository of The University of Melbourne

Author/s:

Hirst, MJ;Griffin, PC;Wu, L-H;Hoffmann, AA

Title:

Testing the environmental warming responses of Brachyscome daisy species using a common garden approach

Date:

2020-03-29

\section{Citation:}

Hirst, M. J., Griffin, P. C., Wu, L. -H. \& Hoffmann, A. A. (2020). Testing the environmental warming responses of Brachyscome daisy species using a common garden approach. AUSTRAL ECOLOGY, 45 (6), pp.717-730. https://doi.org/10.1111/aec.12885.

Persistent Link:

http://hdl.handle.net/11343/275571 